ACTA UNIVERSITATIS CIBINIENSIS - TECHNICAL SERIES

DOI: 10.1515/aucts-2015-0066

Vol. LXVII 2015

\title{
STUDY ON TEMPERATURE DISTRIBUTION IN T FITTINGS - POLYETHYLENE NATURAL GAS PIPES ASSEMBLIES
}

\section{AVRIGEAN Eugen \\ Assistant professor / Ph.D., Faculty of Engineering /Department MEI, "Lucian Blaga" University, Sibiu, Romania, e-mail: eugen.avrigean@ulbsibiu.ro}

\begin{abstract}
The present paper intends to approach theoretically and experimentally an important topic concerning the operational safety of the polyethylene pipes used in natural gas distribution. We discuss the influence of temperature in the high density polyethylene elbows during welding to the polyethylene pipes.
\end{abstract}

Key words: polyethylene, temperature distribution, $\mathrm{T}$ fittings

\section{Introduction}

There are numerous features which prove the advantages of using polyethylene pipes (Figure 1) for the transportation and distribution of natural gas, as opposed to using steel pipes. In addition to the cost of pipes and fittings, the efficiency of a pipeline system is also given by the installation and maintenance costs and by its durability. [5]
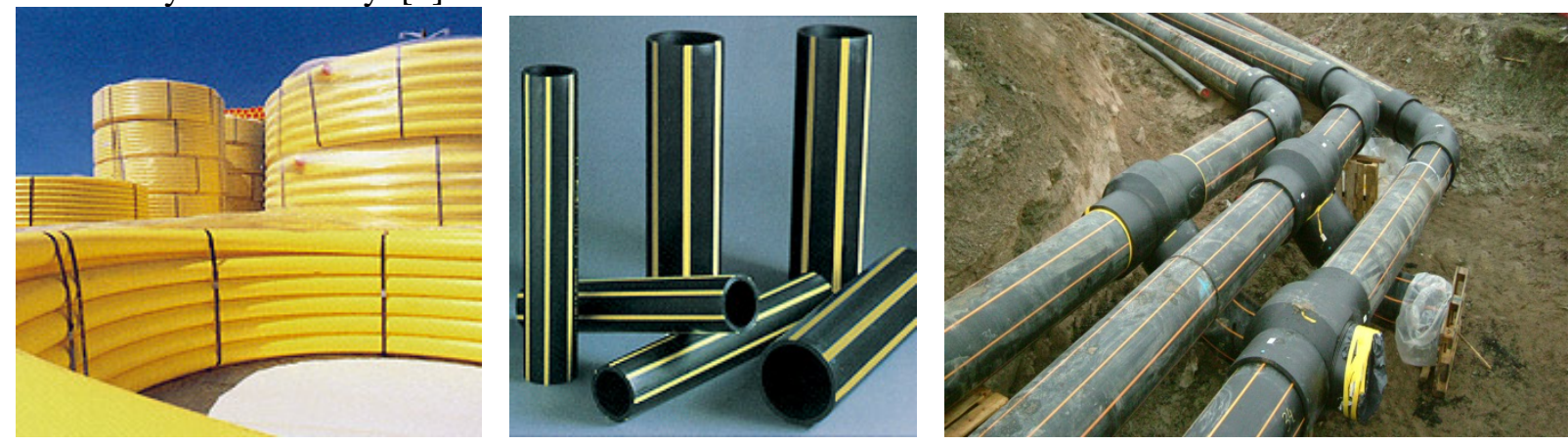

Figure 1. Types of pipes and assemblies used in natural gas distribution

There are certain consequences which appear when the mechanical strength of the polyethylene pipelines and implicitly of the internal operating pressure increases and these are: the thickness of the walls is reduced, having significant economic effects; the productivity of the pipe extrusion operation is increased; the residual stresses due to the welding operation are reduced; there is the possibility of installing pipes in soft soils without needing a sand bed. [3]

Designing polyethylene pipes can not be done only on short-term test results, because of the influence of long-term operating factors, and we refer here to creep and pressure fluctuations. At the same time, we should take into consideration the fittings needed for connecting pipes made of polyethylene or other materials, like steel.

The increase of pressure from 4 to 6 bar (the 8 bar solution), in the new distribution areas, has the purpose of limiting the costs and the number of components (pressure regulators, tubes of different diameters and the respective fittings). [5]

Two methods are used for coupling the polyethylene pipes in the gas distribution systems:

\section{a. Electrofusion Welding}

Welding by means of electrofusion fittings has been increasingly used due to the simplicity of the operation and the high quality of the coupling. The polyethylene fitting is molded and contains an electrical resistance inside its wall which connects the inner surface of the fitting to the external surface of the pipe.

The technology of electrofusion welding is automated. "The human factor" is entirely eliminated by the most modern welding equipment (Figure 2). We need to use ancillary devices for achieving high 
quality joints by using this procedure, such as scrapers for chamfering the ends of the pipe and aligners. Just like for butt welding, we need to clean the contact surfaces on the tube and on the fitting. [5]

\section{b. Butt or Thermofusion Welding}

Each welding equipment manufacturer provides instructions with all the necessary operating details, such as the order of operations, the rules and the detailed regulations (Figure 3), precisely stating the

welding parameters: pressure, time, temperature.

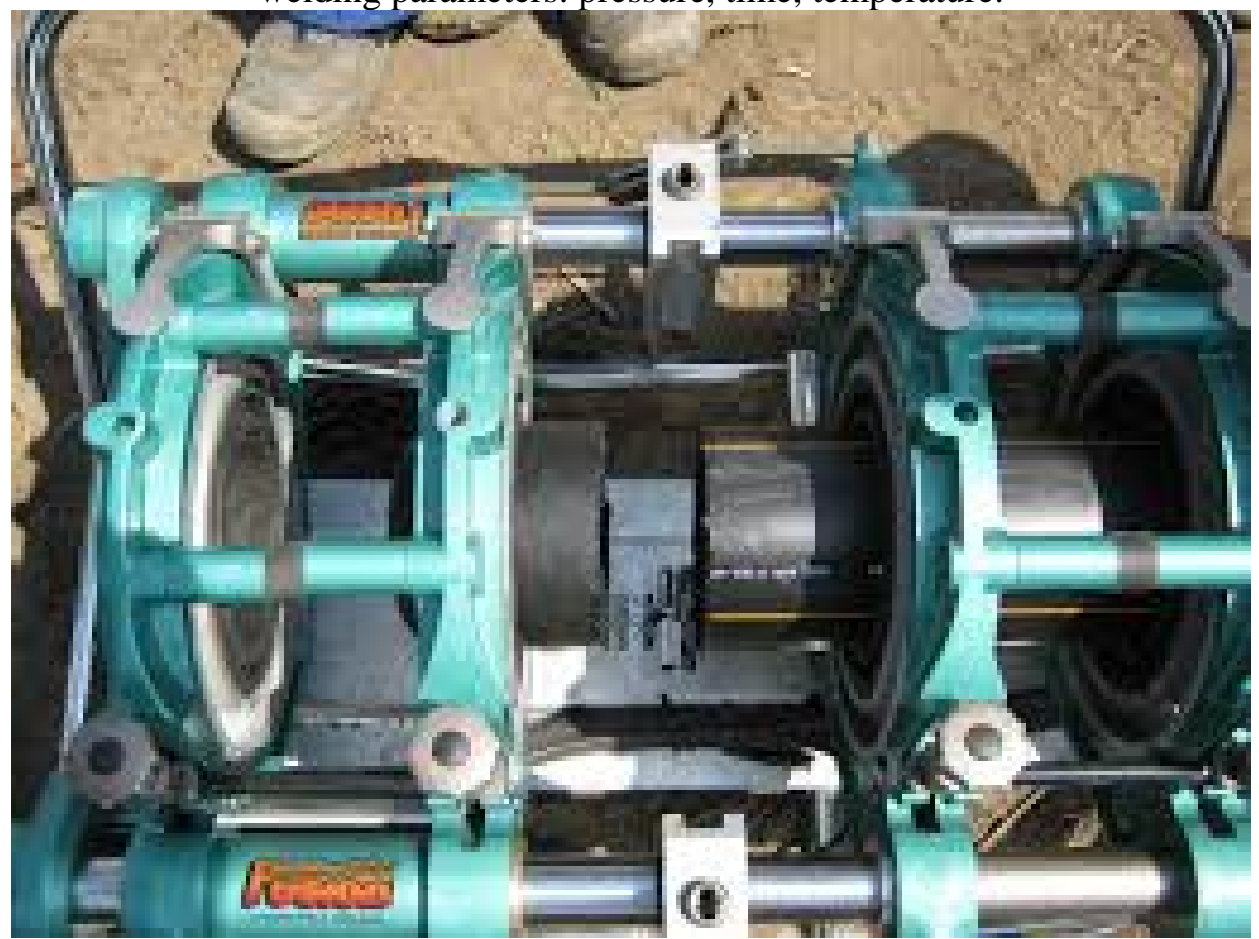

Figura 3. Machine for butt welding pipes and fittings

The basic material and the standard dimension ratio SDR influence the welding parameters. Butt welds are made by means of manual, semiautomatic and automatic machines. This type of welds needs to be done by trained personnel. Butt weld are performed in the following steps: First the pipe ends are fixed in the holders of the welding machine; the ends are cleaned and milled until they are on the same plane; the surfaces to be joint are pre-heated with the heating plate $\left(21^{\circ} \mathrm{C}\right)$; the plate is withdrawn and the two ends are immediately compressed; the joint is cooled in the machine until it reaches a temperature of about $60^{\circ} \mathrm{C}$; the ends of the pipe are released from the clamps of the welding machine. The ambient temperature for this welding must range between 0 and $45^{\circ} \mathrm{C}$. [3]

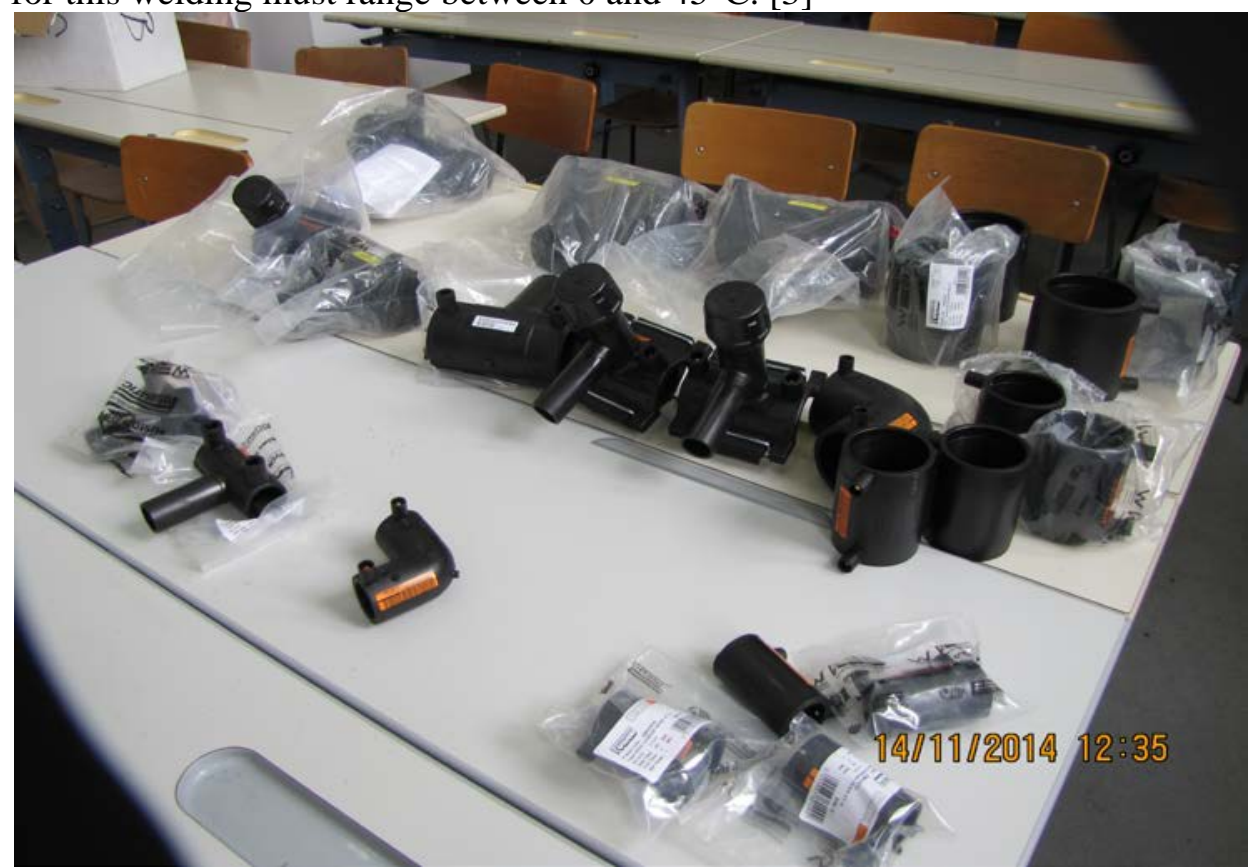

Figure 4. Fittings necessary for electrofusion and butt welding 


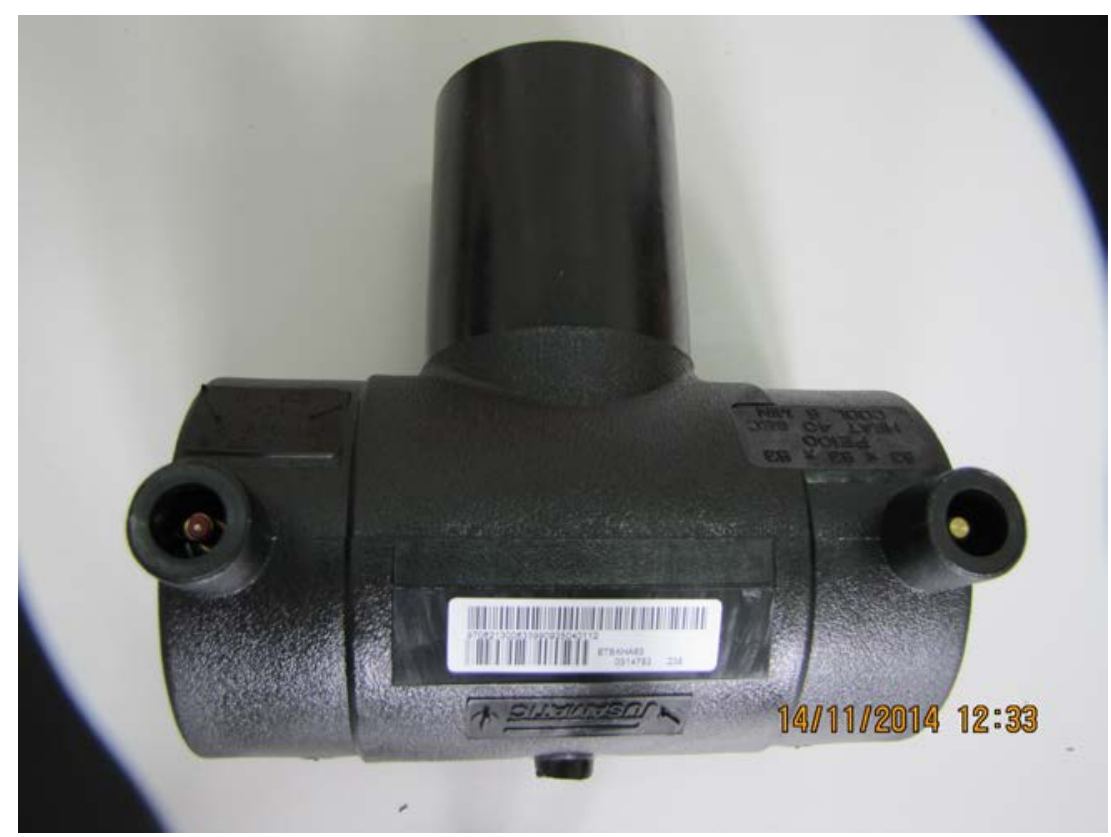

Figure 5. Branch tee for the polyethylene pipelines

The polyethylene fittings have different standardized sizes and are specific to these welding procedures: electrofusion and butt welding. In case of electrofusion, there is an integrated heating element inside the fittings which allows the added material to make the fusion between the connecting fitting and the polyethylene pipe so that they become an entity. The butt welding fittings are slightly different because they do not contain a heater element. They are heated by means of the hot plate. There are both advantages and disadvantages for two types of branching, as follows: the electrofusion fittings are more expensive because of the manufacturing technology that requires the installation of the heating wire, but they the contact surface between the pipes is larger which leads to a greater strength; the butt welding fittings are more inexpensive and can have very large diameters (Figure 4). [4]

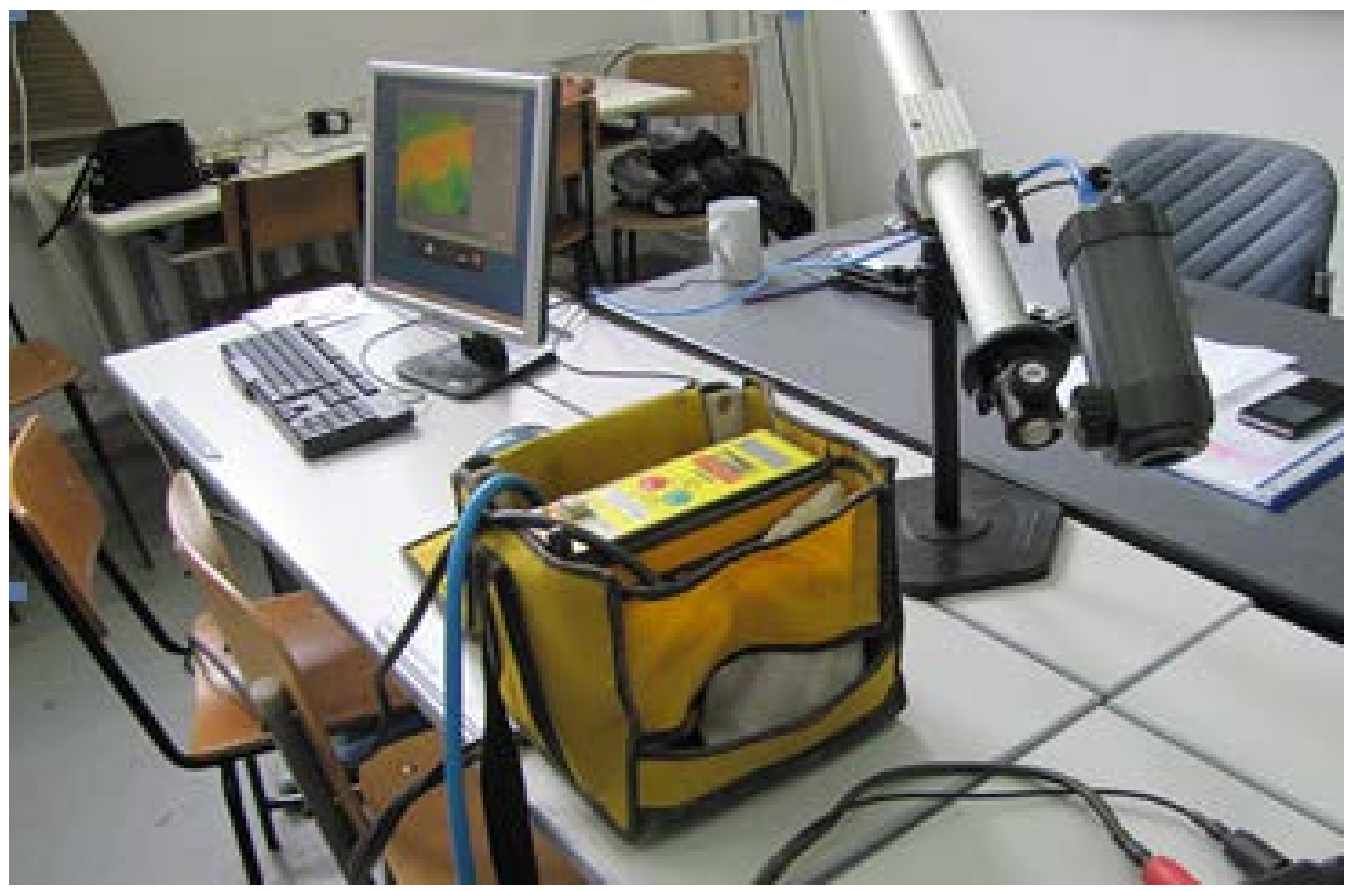

Figure 6. Welding and temperature measuring system

The market studies conducted by means of a questionnaire led to the following results:

- There is no linearity of the assembly;

- The fusion is incomplete; the welding control was not visible;

- The molten material was pushed outward or inward;

- $\quad$ The spires were interrupted or shortened; 
- $\quad$ The ends presented ovality;

- $\quad$ The welding cycle failed to be completed (machine error);

- $\quad$ The fittings for the self-threading branch tee were not sealed. [1]

- The position changed during welding; due to the high temperature, the part detaches from the pipe and the operation might be incorrectly and incompletely accomplished.

Thus, we chose to study an important fitting - the branch tee - that has the functional role of linking (branching) high density polyethylene pipes without depressurization (Figure 5). The branch tee connects with the polyethylene pipe on a relatively small area, therefore we shall further on conduct a study on the variations of temperature in the welding area [2]

\section{The Equipment and the Measuring Instruments. Making measurements.}

We selected the following equipment for our study: 1. Polyethylene welding machine Sbox, manufactured by the Fusion Company in England, which performs polyethylene welds for fittings up to $180 \mathrm{~mm}$ in diameter and follows the welding cycle, so that the machine will record the errors when the welds are not done correctly and will highlight this in the welding protocol; 2. High technology camera for recording the temperature ThermoVision A320 which measures and records temperatures both on a general and a particular area. 3. Software for acquiring the values measured by using the thermal camera helps create both an overall and a detailed image. 4. The welding assembly composed of the high density polyethylene pipe with the diameter DN 63 SDR11 used in natural gas distribution and the branch tee Dn63-63 specific to the pipe branching operation.

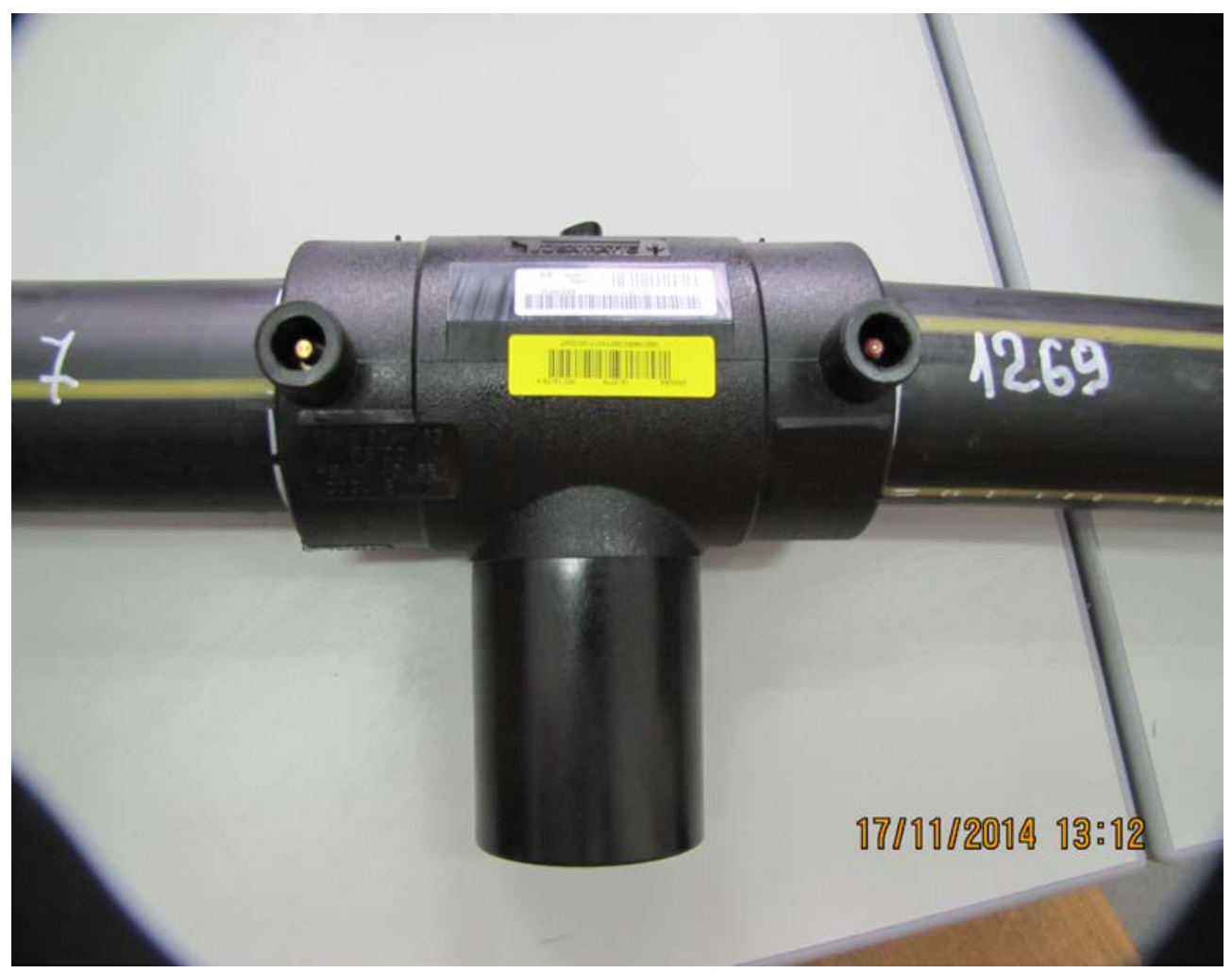

Figure 7. Polyethylene high density pipe Dn 63 SDR11 and the branch tee Dn63-63

We used standard machines and tools and followed the welding technology. We marked the pipe and removed the coating of the Dn63 pipe with a metal scraper in the welding area, which has been pickled with a special pickling solution after which the tee was fixed on the pipe and the welding procedure began.

There were three attempts to measure the work assemblies at an ambient temperature of 22 degrees Celsius. The Sbox polyethylene welding machine allows the automatic adjustment of the operating voltage and the progressive increase of the welding temperature, which is demonstrated in the images taken during the measurements. 


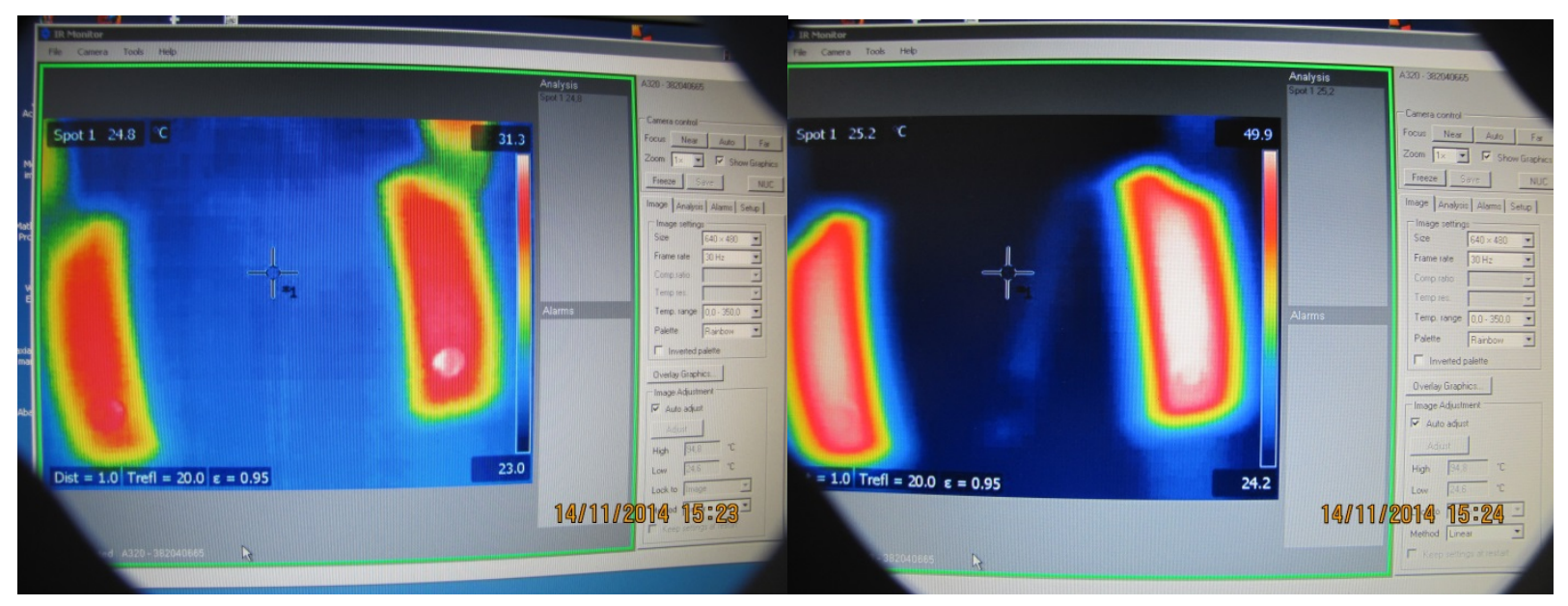

a.

b.

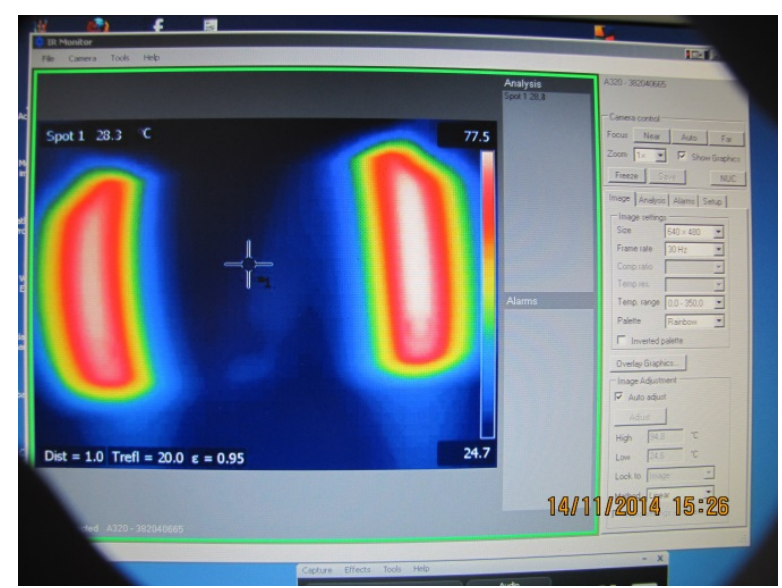

C.

Figure 8. Temperature rise in the three phases of welding: a. Initial, b. Middle, c. Final

By measuring the temperature during the welding process, we can state that it takes 80 seconds to weld the fitting the time is automatically set by the welding machine which receives the information from the fitting and makes the adjustment. The time the temperature rises and stabilizes is 4 minutes and two seconds, longer than the welding time (Figure 9).

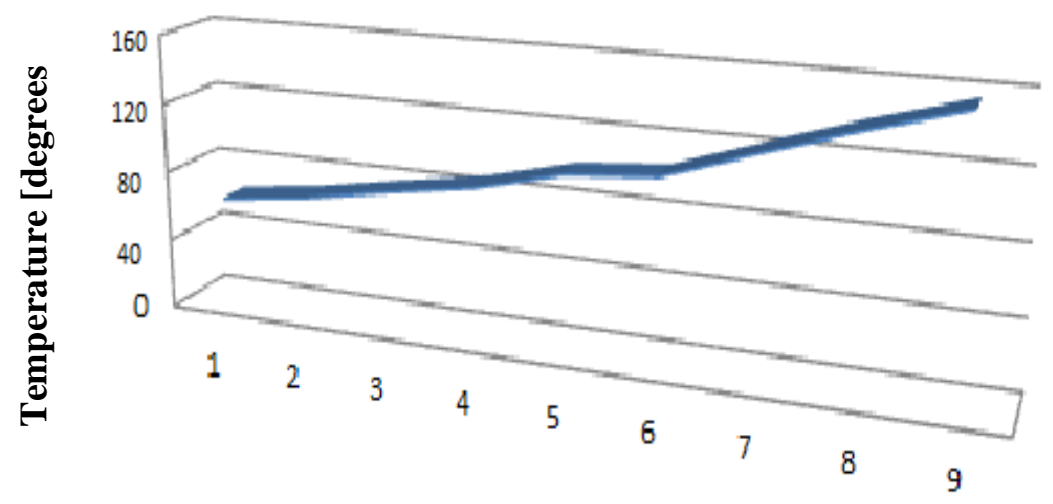

\begin{tabular}{|c|c|}
\hline Time & Temperature \\
\hline [seconds] & [degrees Celsius] \\
\hline 40 & 34.5 \\
\hline 60 & 39.1 \\
\hline 80 & 43.3 \\
\hline 100 & 49.9 \\
\hline 120 & 52.2 \\
\hline 140 & 61.2 \\
\hline 160 & 69.8 \\
\hline 180 & 77.5 \\
\hline
\end{tabular}

Figure 9. Variation of temperature in the welding area depending on time 


\section{Conclusions}

A. We presented the most commonly used welding methods which are the electrofusion and buttthermofusion, and also mentioned their advantages and disadvantages;

B. We tackled the problems that can arise in performing welds so that they could be avoided in practice;

C. The welds were performed by personnel authorized by the State Inspection for Control of Boilers, Pressure Vessels and Hoisting Appliances in welding, so that the results can be validated;

D. The welding time of the studied fitting (branch tee Dn63-63) was 70 seconds, but the temperature had been rising until 160 seconds and reached the maximum value of 77.5 degrees Celsius;

E. We noticed that the area of contact between the pipe and the fitting is relatively small; in conclusion it is recommended to use a tee fastener device which should remain permanently mounted. In case there is a subsequent vertical stress on the tee, the device should not be detached from the pipe, thus increasing the fittings and high density polyethylene pipes' operational safety;

F. We recommend to expand the research to other fittings as well, in order to increase the operational safety of fittings and to develop certain working procedures which would prevent us from improperly performing these operations.

\section{References}

1. Avrigean E. Study on Temperature Distribution in the Jointing Fittings for Polyethylene Natural Gas Pipes. 2015 3rd International Conference on Recent Trends in Materials and Mechanical Engineering (ICRTMME 2015) , January 15-16, 2015, Auckland, New Zealand.

2. Avrigean E. Theoretical and experimental research on the assembly welding of polyethylene fitting - PEHD PE100. Joint International Conference of Doctoral and Post-Doctoral Researchers, Craiova, 12-13 September 2014.

3. Balan, M. L. Contributii la utilizarea procedeului de sudare cap la cap a tevilor de polietilena destinate transportului si distributiei gazelor naturale. Doctoral thesis. Sibiu 2009.

4. D.M. Duse, I. Bondrea, E. Avrigean. Fabricatia integrata de calculator CIM a transmisiilor cardanice. "Lucian Blaga" University Publishing House, Sibiu, 2003.

5. Murariu, A.C. Influenta imperfectiunilor imbinarilor sudate ale structurilor din polietilena de inalta densitate. Doctoral thesis. Timisoara, 2008.

6. ISO 12176-2:2000 - Plastics pipes and fittings - Equipment for fusion jointing polyethylene systems - Part 2: Electrofusion

\section{Acknowledgements}

The paper was sustained by the strategic grant POSDRU/159/1.5/S/133255, Project ID 133255 (2014), co-financed by the European Social Fund within the Sectorial Operational Program Human Resources Development 2007 - 2013. 